\title{
Effects of Phosphorus on Microstructure and Fluidity of Sn-0.7Cu-0.05Ni Lead-Free Solder
}

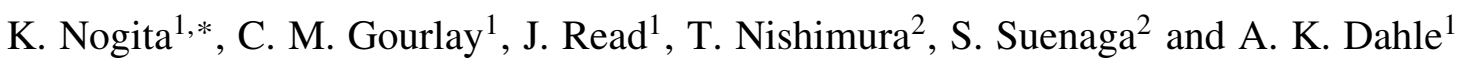 \\ ${ }^{1}$ Materials Engineering, The University of Queensland, Brisbane 4072, Australia \\ ${ }^{2}$ Nihon Superior Co., Ltd, NS Bldg., Suita 564-0063, Japan
}

\begin{abstract}
Phosphorus is often added to wave-solder baths as an anti-oxidation agent. Despite this practice, there is little information on how phosphorus influences the solidification and flow properties of new lead-free solders such as $\mathrm{Sn}-0.7 \mathrm{Cu}-0.05 \mathrm{Ni}$. This paper investigates the effects of phosphorus content on microstructure and maximum fluidity length in $\mathrm{Sn}-0.7 \mathrm{Cu}-0.05 \mathrm{Ni}-x \mathrm{P}$ alloys containing $0-0.08$ mass $\%$ phosphorous. $\mathrm{Ppm}$ levels of phosphorous are found to cause $\mathrm{Sn}-x \mathrm{P}, \mathrm{Ni}-x \mathrm{P}-(\mathrm{Sn})$ and $\mathrm{Cu}-x \mathrm{P}-(\mathrm{Sn})$ intermetallic compounds to form in the liquid solder. The IMCs are less dense than liquid $\mathrm{Sn}$ and float towards the surface of the melt driven by buoyancy. It is shown that P-free $\mathrm{Sn}-0.7 \mathrm{Cu}-0.05 \mathrm{Ni}$ solidifies with a near-eutectic microstructure whereas, when $\mathrm{P}$ is added to this alloy, a significant volume fraction of primary Sn dendrites form once the $\mathrm{P}$ content exceeds $\sim 0.01$ mass $\%$ P. It is further shown that $\mathrm{P}$ additions decrease the ability of $\mathrm{Sn}-0.7 \mathrm{Cu}-0.05 \mathrm{Ni}$ to flow as it solidifies. [doi:10.2320/matertrans.MBW200713]
\end{abstract}

(Received October 10, 2007; Accepted December 13, 2007; Published February 25, 2008)

Keywords: lead-free soldering, nickel, phosphorus, eutectic, solidification

\section{Introductions}

Since the discovery that the addition of $0.04-0.1$ mass $\% \mathrm{Ni}$ to $\mathrm{Sn}-0.7$ mass \% Cu alloys improves soldering properties, the $\mathrm{Sn}-\mathrm{Cu}-\mathrm{Ni}$ alloy system has become one of the most promising lead-free soldering alloys available. ${ }^{1,2)}$ The addition of between $0.04-0.1$ mass\% $\mathrm{Ni}$ has been shown to improve the soldering characteristics of $\mathrm{Sn}-\mathrm{Cu}$ alloys by reducing the tendency for "bridging" and to improve the interface between the solder and the base metal. ${ }^{3)}$ The Ni acts to increase the ability of the solder to flow as it solidifies as shown in previous research using the vacuum fluidity test. $\left.{ }^{4,5}\right)$ The improved capacity of $\mathrm{Sn}-0.7 \mathrm{Cu}-(0.04-0.1) \mathrm{Ni}$ to flow as it solidifies is thought to be beneficial during wave soldering, when it is important that the solder is able to completely fill joints and cover connections, and for excess solder to drain away to leave tidy fillets.

Phosphorus is commonly added to solders as an antioxidation agent during wave soldering with $\mathrm{Sn}-37 \mathrm{~Pb}$ and some new lead-free solder alloys. However, there is little information on how phosphorus influences the solidification and flow properties of $\mathrm{Sn}-\mathrm{Cu}-\mathrm{Ni}$ solders. The purpose of the current research is to investigate the effect of phosphorus on microstructure and maximum fluidity length of $\mathrm{Sn}-0.7 \mathrm{Cu}-$ $0.05 \mathrm{Ni}-(\mathrm{P})$ alloys.

\section{Experimental}

Six alloys were used in this study: $\mathrm{Sn}-0.7 \mathrm{Cu}, \mathrm{Sn}-0.7 \mathrm{Cu}-$ $0.05 \mathrm{Ni}$ and four $\mathrm{Sn}-0.7 \mathrm{Cu}-\mathrm{Ni}-\mathrm{P}$ alloys containing $0-0.08$ mass $\%$ P. P was mixed with $\mathrm{Sn}-0.7 \mathrm{Cu}-0.05 \mathrm{Ni}$ by adding a Sn5 mass $\% \mathrm{P}$ master alloy to pre-alloyed $\mathrm{Sn}-0.7 \mathrm{Cu}-0.05 \mathrm{Ni}$ ingot. The $\mathrm{Sn}-0.7 \mathrm{Cu}-0.05 \mathrm{Ni}$ was placed in a clay-graphite crucible and heated to $290^{\circ} \mathrm{C}$ in an electric resistance furnace. The melt was held at this temperature for a minimum of two hours. The Sn-5 mass \% P master alloy was then added and the

*Corresponding author, E-mail: k.nogita@uq.edu.au melt was stirred vigorously by hand for approximately one minute to aid mixing. The system was then held at $290^{\circ} \mathrm{C}$ for a further hour. Next, the dross was removed from the surface of the melt and two samples of the alloy were collected concurrently in boron nitride coated tapered stainless steel moulds using the method outlined in reference. ${ }^{5)}$ One of the samples was used to record the cooling curve using an N-type thermocouple. The other sample was left to solidify and was later used for metallographic examination. This technique resulted in a cooling rate of $0.5^{\circ} \mathrm{C} \cdot \mathrm{s}^{-1}$ prior to nucleation of the first solid. Samples for chemical analysis were taken from the top of the clay-graphite crucible, after dross had been removed from the melt surface.

Samples were sectioned, mounted in resin and then ground using SiC paper (120-2400 grit). The samples were given a final grinding on 4000 grit $\mathrm{SiC}$ paper with soap as a lubricant to prevent the embedding of $\mathrm{SiC}$ particles, before a final polish with $0.05 \mu \mathrm{m}$ colloidal silica. Optical micrographs were taken of these samples before and after etching in a $5 \%$ $\mathrm{HNO}_{3}$ solution. A JEOL 6460LA scanning electron microscope was used to take high magnification backscattered electron images (BEI) and energy dispersive spectra (EDS) of the samples with a particular focus on determining the location of $\mathrm{P}, \mathrm{Ni}$ and $\mathrm{Cu}$ in the microstructures.

The extent to which the alloys could flow as they solidify was studied using the vacuum fluidity test (Ragone method), ${ }^{6,7)}$ where the liquid alloy is forced to flow through a relatively cold tube so that the alloy solidifies as it flows. Experimental parameters were held at:

(1) Mass of alloy in crucible: $1500 \mathrm{~g} \pm 0.2 \mathrm{~g}$

(2) Melt temperature: $T_{\text {liq }}+40^{\circ} \mathrm{C} \pm 0.5^{\circ} \mathrm{C} \quad$ (average $\left.267.7^{\circ} \mathrm{C}\right)$

(3) Ambient temperature: $22.7^{\circ} \mathrm{C} \pm 2.5^{\circ} \mathrm{C}$

(4) Partial vacuum: $-80 \mathrm{kPa} \pm 2 \mathrm{kPa}$

(5) Outer diameter of borosilicate glass tube: $6 \mathrm{~mm} \pm$ $0.15 \mathrm{~mm}$

(6) Thickness of borosilicate glass tube: $1.5 \mathrm{~mm} \pm 0.1 \mathrm{~mm}$ Further details of the maximum fluidity length experimental 

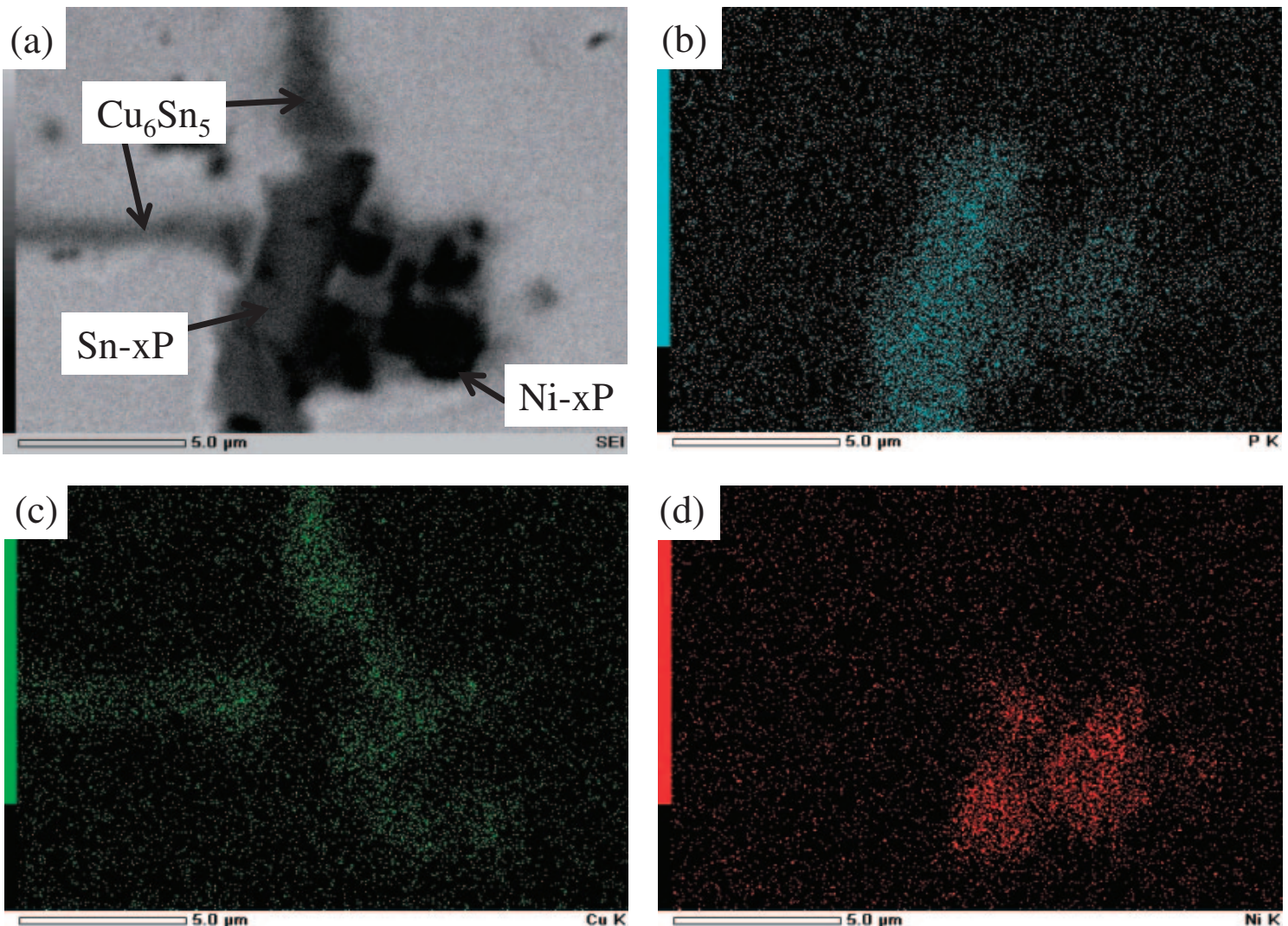

Fig. 1 SEM/EDS elemental mapping from the top of a cooling-cup sample with nominal composition of $\mathrm{Sn}-0.7 \mathrm{Cu}-0.05 \mathrm{Ni}-0.07 \mathrm{P}$. (a) secondary electron SEM image, (b) P, (c) $\mathrm{Cu}$ and (d) Ni.
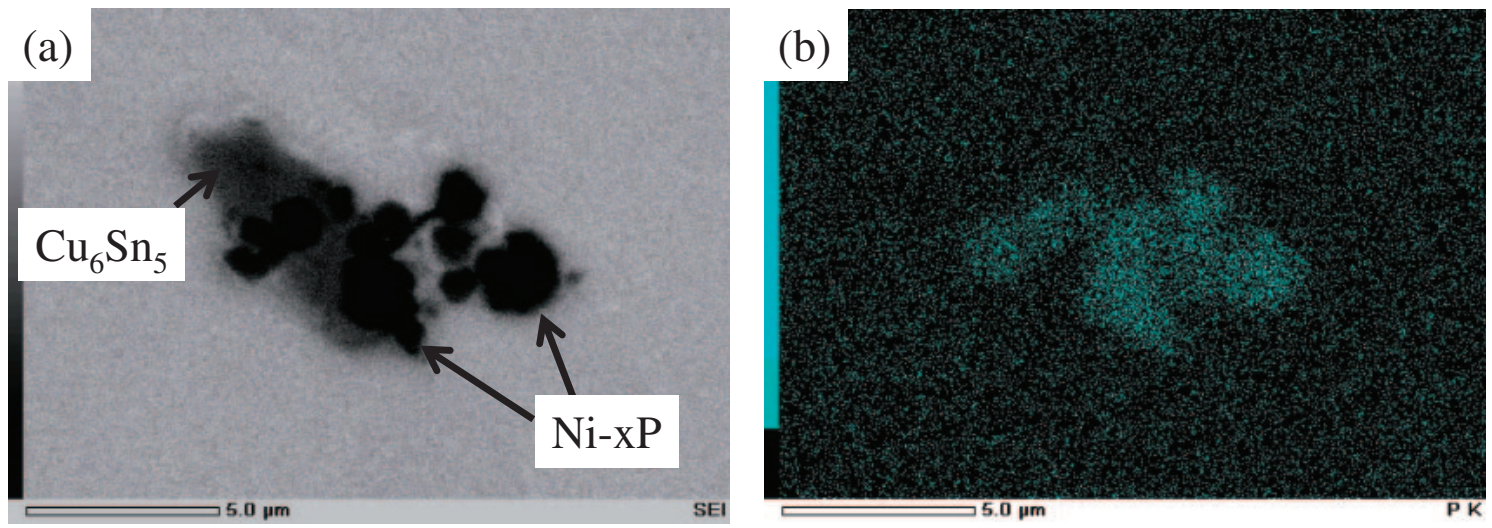

\section{(c)}

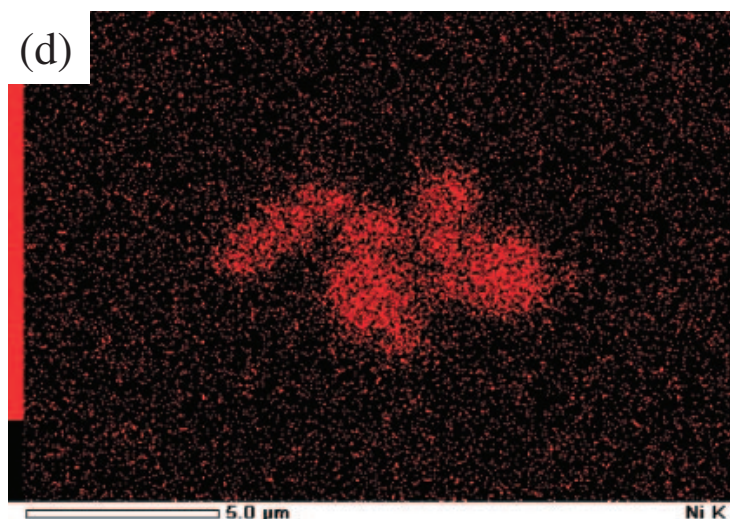

Fig. 2 SEM/EDS elemental mapping from the centre of a cooling-cup sample with nominal composition of Sn-0.7Cu-0.05Ni-0.07P. (a) secondary electron SEM image, (b) P, (c) $\mathrm{Cu}$ and (d) Ni. 


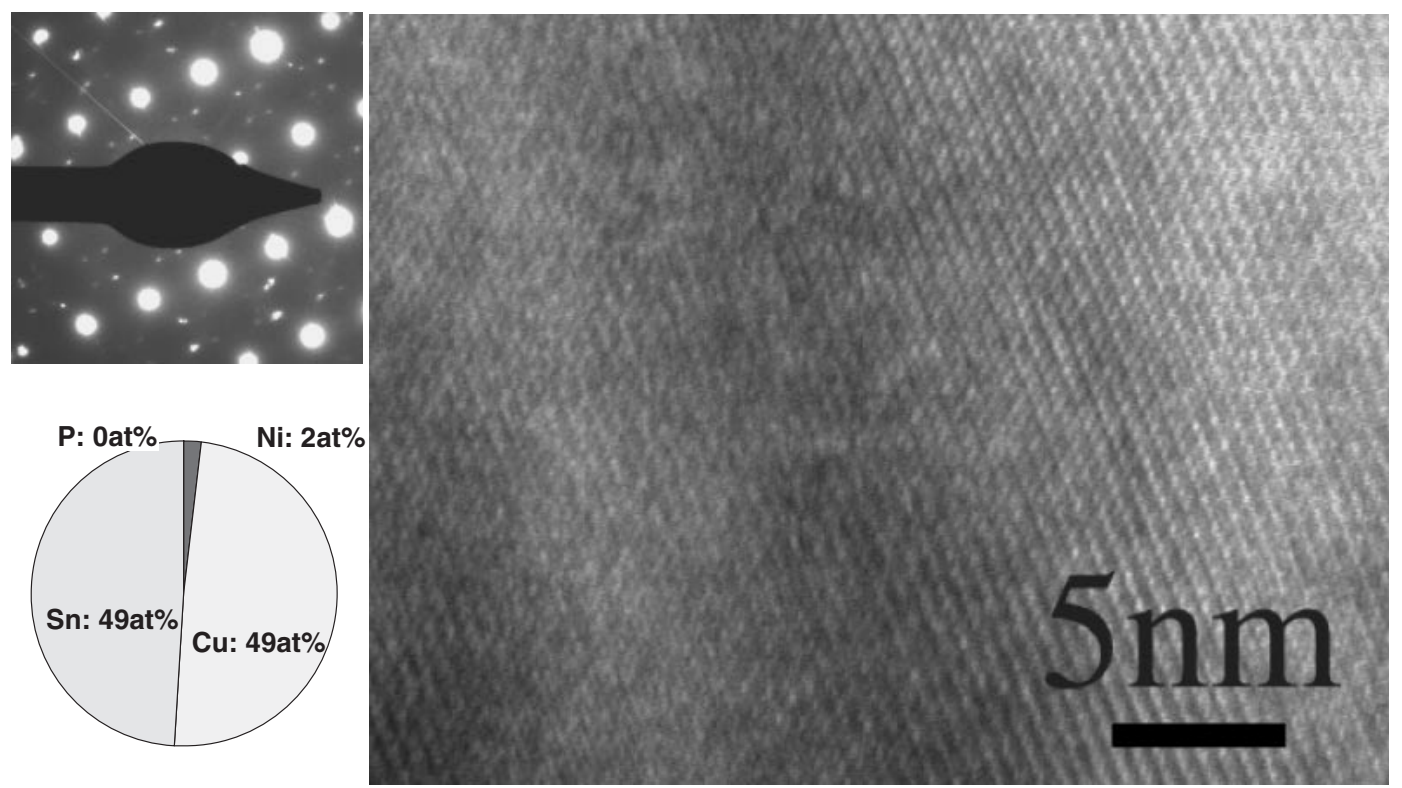

Fig. 3 Lattice image and corresponding selected area electron diffraction pattern (SAD) taken from an intermetalic at the flow tip of sample with nominal composition $\mathrm{Sn}-0.7 \mathrm{Cu}-0.05 \mathrm{Ni}-0.07 \mathrm{P}$. The crystal structure is monoclinic, and EDS point analysis yielded $\mathrm{Sn}: 49$ at $\%, \mathrm{Cu}: 49$ at\%, Ni:2 at\% and P:0 at $\%$, indicating that the phase is $\eta^{\prime}-(\mathrm{Cu}, \mathrm{Ni})_{6} \mathrm{Sn}_{5}{ }^{\prime}$.

Table 1 Chemical compositions of the samples (mass\%) measured by ICP-AES.

\begin{tabular}{|c|c|c|c|c|c|c|}
\hline \multirow{2}{*}{ Sample name } & \multicolumn{3}{|c|}{ Nominal compositions } & \multicolumn{3}{|c|}{ Measured compositions } \\
\hline & $\mathrm{Cu}$ & $\mathrm{Ni}$ & $\mathrm{P}$ & $\mathrm{Cu}$ & $\mathrm{Ni}$ & $\mathrm{P}$ \\
\hline $\mathrm{Sn} 0.7 \mathrm{Cu}$ & 0.6975 & 0.0032 & 0.000 & 0.6975 & 0.0032 & 0.0002 \\
\hline $\mathrm{Sn} 0.7 \mathrm{Cu} 0.05 \mathrm{Ni} 0.007 \mathrm{P}$ & 0.6944 & 0.0502 & 0.007 & 0.7015 & 0.0501 & 0.0023 \\
\hline $\mathrm{Sn} 0.7 \mathrm{Cu} 0.05 \mathrm{Ni} 0.02 \mathrm{P}$ & 0.6926 & 0.0501 & 0.020 & 0.6983 & 0.0457 & 0.0087 \\
\hline $\mathrm{Sn} 0.7 \mathrm{Cu} 0.05 \mathrm{Ni0} .07 \mathrm{P}$ & 0.6857 & 0.0496 & 0.070 & 0.6817 & 0.0330 & 0.0212 \\
\hline $\mathrm{Sn} 0.7 \mathrm{Cu} 0.05 \mathrm{Ni0} 0.08 \mathrm{P}$ & 0.6843 & 0.0495 & 0.080 & 0.6644 & 0.0371 & 0.0253 \\
\hline
\end{tabular}

procedure are outlined in reference. ${ }^{4)}$ Experiments were repeated six times for each composition. Fully solidified fluidity samples were later prepared for optical microscopy and field emission transmission electron microscopy (FETEM: Tecnia20). High resolution lattice images and electron diffraction patterns were used to study the intermetallic phases and EDS was used for elemental analysis.

\section{Results and Discussion}

\subsection{Intermetallic compounds}

Adding ppm levels of phosphorous to $\mathrm{Sn}-0.7 \mathrm{Cu}-0.05 \mathrm{Ni}$ was found to influence the intermetallic compounds that form during solidification. SEM-EDS analysis of cooling-cup samples revealed the presence of various P-bearing intermetallic particles. Figures 1(a)-(d) and 2(a)-(d) show SEM/ EDS element maps from a sample with nominal composition $\mathrm{Sn}-0.7 \mathrm{Cu}-0.05 \mathrm{Ni}-0.07 \mathrm{P}$. Figure 1 is from the top of the sample and appears to contain a number of distinct intermetallic phases: (i) the $\mathrm{Cu}$-rich regions containing only background-levels of $\mathrm{Ni}$ or $\mathrm{P}$ are probably $\mathrm{Cu}_{6} \mathrm{Sn}_{5}$; (ii) the $\mathrm{P}$ rich region containing only background-levels of $\mathrm{Ni}$ and $\mathrm{Cu}$ is probably a Sn- $x \mathrm{P}$ phase; and (iii) the region rich in $\mathrm{P}$ and $\mathrm{Ni}$ is likely to be one of the wide range of binary $\mathrm{Ni}-x \mathrm{P}$ or ternary

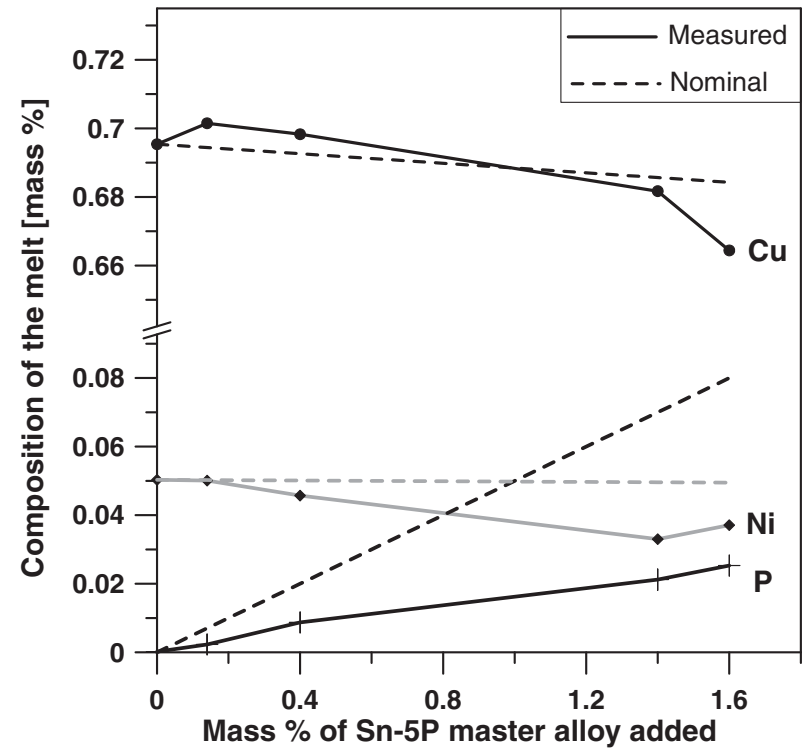

Fig. 4 The measured chemical composition of the melt as a function of the amount of master alloy added. Dashed lines indicate the nominal composition. 

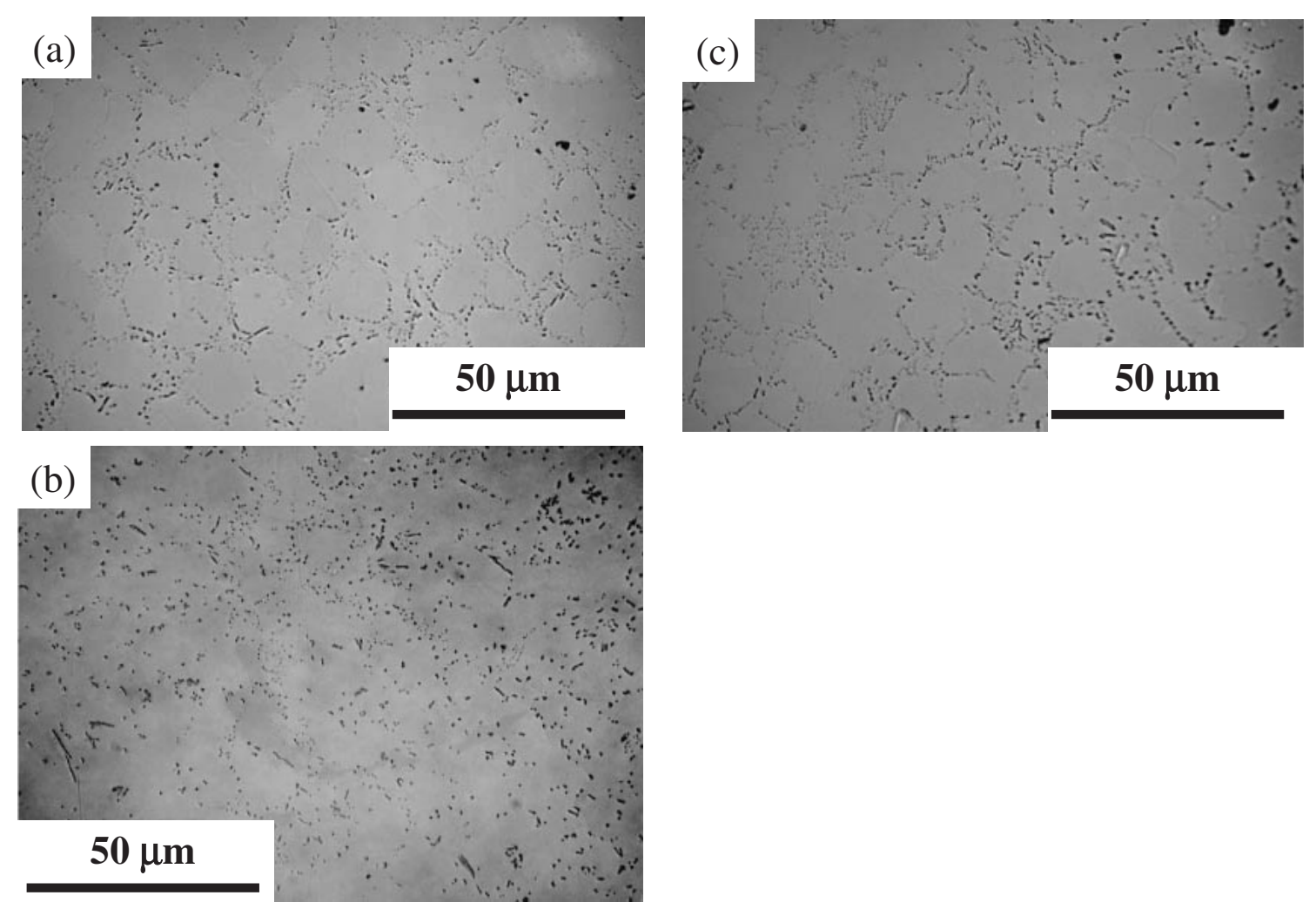

Fig. 5 Typical microstructures from near the flow tip of maximum fluidity length samples. (a) $\mathrm{Sn}-0.7 \mathrm{Cu},(b) \mathrm{Sn}-0.7 \mathrm{Cu}-0.05 \mathrm{Ni}$, and (c) nominal composition Sn-0.7Cu-0.05Ni-0.07P (measured Sn-0.68Cu-0.033Ni-0.021P).

Ni- $x \mathrm{P}-(\mathrm{Sn})$ phases that are known to exist. ${ }^{8,9)}$ Figure 2 is from the centre of the sample and appears to contain two distinct intermetallic compounds: (i) $\mathrm{Cu}$-rich regions are probably $\mathrm{Cu}_{6} \mathrm{Sn}_{5}$, and (ii) the Ni-rich region containing $\mathrm{P}$ is probably a binary Ni- $x$ P or ternary Ni- $x \mathrm{P}-(\mathrm{Sn})$ phase, ${ }^{8,9)}$ similar to Fig. 1. Further work is required to isolate and identify the phases present. A significantly higher volume fraction of P-bearing compounds was observed in the top regions than elsewhere in cooling-cup samples.

Figure 3 shows the lattice image, selected area diffraction pattern (SAD) and EDS results from an intermetallic at the flow tip of a fluidity sample with nominal composition $\mathrm{Sn}$ $0.7 \mathrm{Cu}-0.05 \mathrm{Ni}-0.07 \mathrm{P}$. The TEM/SAD result shows that the phase has a monoclinic crystal structure and the EDS analysis yielded a composition of $\mathrm{Sn}_{49} \mathrm{Cu}_{49} \mathrm{Ni}_{2}$. The $\mathrm{Sn}$ rich $\mathrm{Sn}-\mathrm{Cu}$ binary phase diagram, ${ }^{10,11)}$ shows that $\mathrm{Cu}_{6} \mathrm{Sn}_{5}$ has two crystal structures, with an allotropic transformation at $186^{\circ} \mathrm{C}$. For the compositions studied here, the high temperature hexagonal $\eta$ $\mathrm{Cu}_{6} \mathrm{Sn}_{5}$ phase is expected to form during solidification and to transform to the low temperature monoclinic $\eta^{\prime}-\left(\mathrm{Cu}, \mathrm{Ni}_{6}\right)_{6} \mathrm{Sn}_{5}{ }^{\prime}$ phase on cooling. ${ }^{11-13)}$ The monoclinic $\mathrm{Sn}_{49} \mathrm{Cu}_{49} \mathrm{Ni}_{2}$ intermetallic in Fig. 3 is consistent with the room temperature monoclinic $\eta^{\prime}-(\mathrm{Cu}, \mathrm{Ni})_{6} \mathrm{Sn}_{5}{ }^{\prime}$ phase. ${ }^{11-13)}$ No phosphorus containing intermetallics were found in fluidity samples.

\subsection{Composition}

Table 1 shows the melt composition as measured by ICPAES. The measured compositions do not correlate closely with the nominal compositions, despite the fact that the alloys were made simply by mixing a Sn-5P master alloy with pre- alloyed $\mathrm{Sn}-0.7 \mathrm{Cu}-0.05 \mathrm{Ni}$ ingot. Note that the quoted nominal values already account for the decrease in Ni due to the Sn-5P master alloy addition. Table 1 and Fig. 4 show that the measured Ni contents are lower than the nominal values, and adding increasing Sn-P master alloy tends to amplify this difference. The highest $\mathrm{P}$ additions also led to a reduction in $\mathrm{Cu}$ content in the melt. Additionally, the composition of $\mathrm{P}$ in the melt was significantly lower than the nominal composition.

During experiments, it was noticed that the surface dross of phosphorous containing alloys had a much greater lustre than that in the $\mathrm{Sn}-0.7 \mathrm{Cu}$ or $\mathrm{Sn}-0.7 \mathrm{Cu}-0.05 \mathrm{Ni}$ alloys. Combining this observation with the presence of a high volume fraction of P-bearing particles at the top of samples in $\S 3.1$, it is likely that low-density P-bearing particles floated towards the surface of the melt and were removed when dross was removed from the melt. As dross was removed before chemical analysis and cup samples were taken and before fluidity experiments were run, adding $\mathrm{P}$ changes the $\mathrm{P}, \mathrm{Ni}$ and $\mathrm{Cu}$ contents during these experiments. The removal of dross is also common practice in industrial wave-soldering operations.

\subsection{Microstructure}

Figures 5 and 6 show optical micrographs from fluidity samples and three locations within cooling-cup samples, respectively. Although the scale of the microstructure and the cooling rate during solidification differs between the two experiments, each alloy exhibited similar microstructural characteristics. The microstructure of binary $\mathrm{Sn}-0.7 \mathrm{Cu}$ con- 


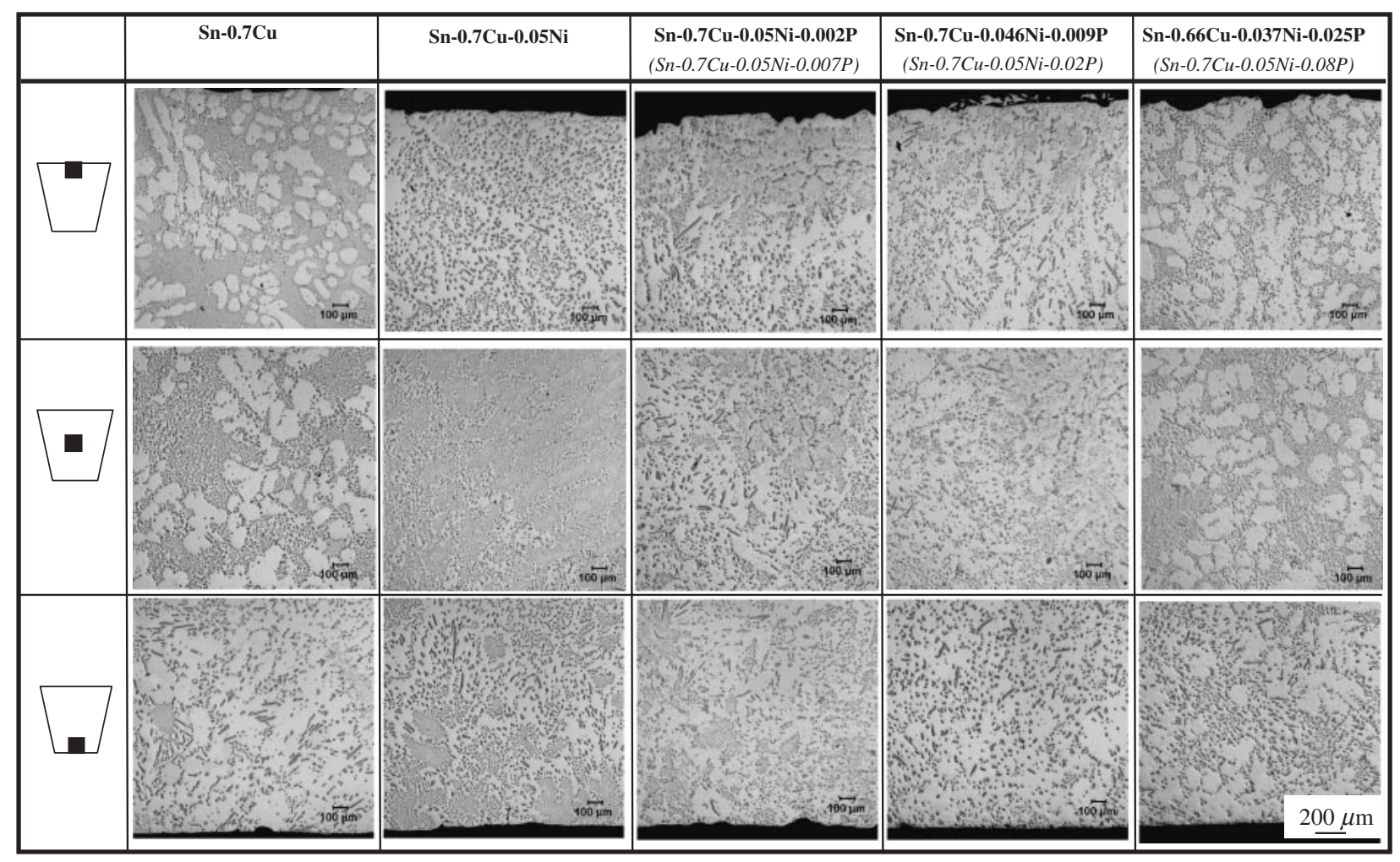

Fig. 6 Optical micrographs from the top, middle and bottom of cooling-cup samples made using five Sn-0.7Cu-xNi-yP alloys. Compositions are in mass\% with measured compositions in bold and nominal compositions in bracketed italics.

sists of primary Sn dendrites and interdendritic eutectic. In $\mathrm{Sn}-0.7 \mathrm{Cu}-0.05 \mathrm{Ni}$ samples no dendrites are discernable and the intermetallics are distributed more evenly throughout the microstructure. In nominal $\mathrm{Sn}-0.7 \mathrm{Cu}-0.05 \mathrm{Ni}-x \mathrm{P}$ alloys, the microstructure was found to depend on the $\mathrm{P}$ content. At a measured level of 0.002 mass $\% \mathrm{P}$, the microstructure appears near-eutectic and Sn-dendrites were not observed. At the higher measured levels of 0.021 and 0.025 mass $\% \mathrm{P}$, however, the microstructure is clearly hypoeutectic, containing a significant volume fraction of Sn dendrites.

Previous research by the authors ${ }^{5,14)}$ has shown that, as the $\mathrm{Ni}$ content in $\mathrm{Sn}-0.7 \mathrm{Cu}-x \mathrm{Ni}$ decreases from 0.05 mass $\%$, the volume fraction of primary Sn dendrites in the microstructure increases. This result was shown to be consistent with the phase equilibria of the $\mathrm{Sn}-\mathrm{Cu}-\mathrm{Ni}$ system, ${ }^{15)}$ where $\mathrm{Sn}-0.7 \mathrm{Cu}$ $0.05 \mathrm{Ni}$ is closer to a eutectic valley than $\left.\mathrm{Sn}-0.7 \mathrm{Cu} .{ }^{4,5}\right)$ However, the increased volume fraction of Sn-dendrites with increasing $\mathrm{P}$ content in Figs. 5 and 6 cannot be solely explained by the decreased $\mathrm{Ni}$ content, as the $\mathrm{P}$ containing samples in Figs. 5(c) and 6 contain a higher volume fraction of $\mathrm{Sn}$ dendrites than that previously reported for P-free Sn$0.7 \mathrm{Cu}-(0.03-0.04) \mathrm{Ni}$ alloys. ${ }^{5}$

\subsection{Maximum fluidity Length}

Figure 7 (a) shows that adding $\mathrm{P}$ to a $\mathrm{Sn}-0.7 \mathrm{Cu}-0.05 \mathrm{Ni}$ melt significantly decreases the ability of the alloy to flow as it solidifies. $\mathrm{P}$ additions decrease the maximum fluidity length with the most dramatic decrease in the range 20 to $90 \mathrm{ppm} P$ (measured composition). Extensive studies on the influence of alloy composition on maximum fluidity length $\left(L_{\mathrm{f}}\right)$ have shown that pure metals and eutectic alloys have the highest values of $L_{\mathrm{f}}$, and that $L_{\mathrm{f}}$ decreases as the composition deviates from these points. ${ }^{6,7,16)}$ The microstructural observations in $\$ 3.3$ revealed that adding increasing levels of $P$ to $\mathrm{Sn}-0.7 \mathrm{Cu}-0.05 \mathrm{Ni}$ melts leads to a transition from a neareutectic microstructure to one containing a significant volume fraction of $\mathrm{Sn}$ dendrites. Therefore, the decreasing $L_{\mathrm{f}}$ with increasing $\mathrm{P}$ additions appears to occur because the composition moves away from a eutectic valley.

Figure 7(a) does not show the change in $L_{\mathrm{f}}$ at constant $\mathrm{Ni}$ content, however, because $\mathrm{P}$ additions reduced the Ni content of the melt (see Table 1 and Fig. 4). The $L_{\mathrm{f}}$ of $\mathrm{Sn}-0.7 \mathrm{Cu}-x \mathrm{Ni}$ alloys has previously been shown to be highly sensitive to the $\mathrm{Ni}$ content, ${ }^{4,5,17)}$ and it is therefore important to assess the role of the changing $\mathrm{Ni}$ content on the change in $L_{\mathrm{f}}$ with $\mathrm{P}$ additions. Figure 7(b) shows the influence of Ni content on $L_{\mathrm{f}}$ in P-free $\mathrm{Sn}-0.7 \mathrm{Cu}-x \mathrm{Ni}$ using data from reference. ${ }^{4)}$ Figure 7(b) also shows the P-containing data from Fig. 6(a), where $L_{\mathrm{f}}$ values are plotted against the measured Ni content. In both cases a marked transition in $L_{\mathrm{f}}$ occurs with increasing $\mathrm{Ni}$ content, and this transition occurs at higher Ni content in the P-containing alloys. However, similar to Fig. 7(a), Fig. 7(b) does not show $L_{\mathrm{f}} v s$. Ni at constant $\mathrm{P}$, and therefore Figs. 7(a) and (b) do not allow us to decouple the influences of $\mathrm{P}$ and $\mathrm{Ni}$ on $L_{\mathrm{f}}$.

\section{Conclusions}

0-800 ppm $\mathrm{P}$ has been added to liquid $\mathrm{Sn}-0.7 \mathrm{Cu}-0.05 \mathrm{Ni}$ alloys in the form of a Sn-5 mass\% P master alloy. P additions were found to influence following:

(1) Ni- $x \mathrm{P}-(\mathrm{Sn}), \mathrm{Cu}-x \mathrm{P}-(\mathrm{Sn})$ and $\mathrm{Sn}-x \mathrm{P}$ intermetallic com- 
(a)

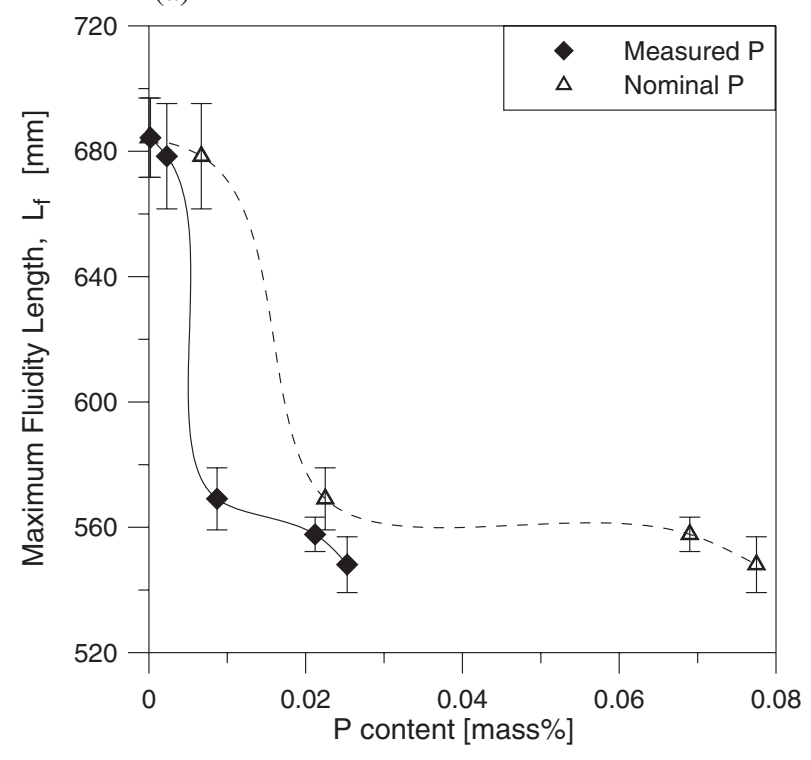

(b)

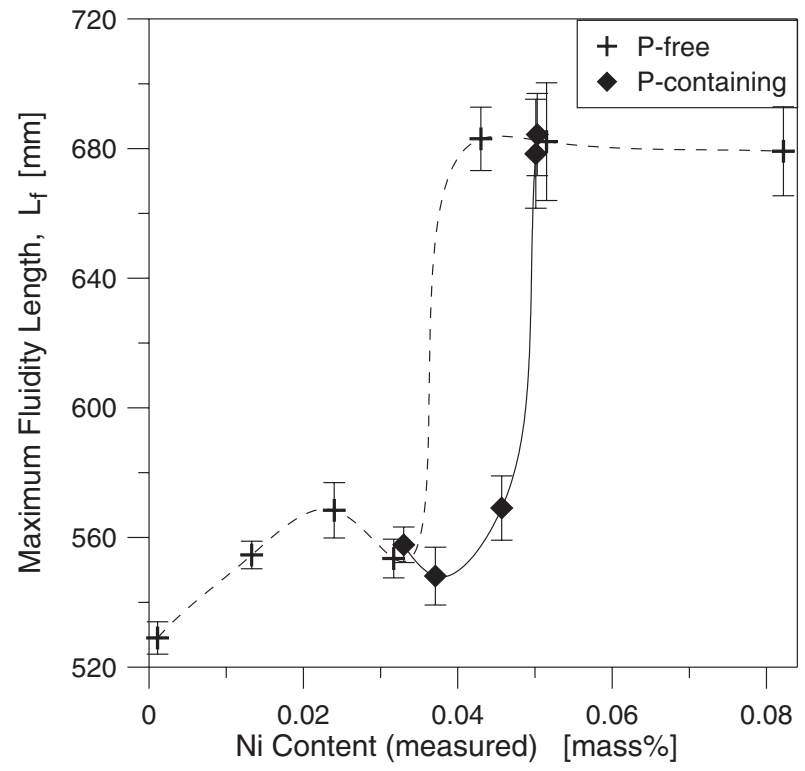

Fig. 7 Maximum fluidity length $\left(L_{\mathrm{f}}\right)$ in Sn- $0.7 \mathrm{Cu}-x \mathrm{Ni}-\mathrm{yP}$ alloys using the experimental conditions given in reference 4 . (a) $L_{\mathrm{f}}$ versus P content, (b) $L_{\mathrm{f}}$ versus Ni content.

pounds were observed in P-containing alloys. A higher volume fraction of these phases was distributed near the top surface of samples, indicating that these particles float in liquid Sn. These phases can be removed from the melt when dross is removed.

(2) TEM/SAD analysis of intermetallics in fluidity samples demonstrated the presence of monoclinic $\eta^{\prime}$ $(\mathrm{Cu}, \mathrm{Ni})_{6} \mathrm{Sn}_{5}{ }^{\prime}$ in $\mathrm{Sn}-0.7$ mass\% $\mathrm{Cu}-0.05$ mass\% Ni-0.07 mass $\% \mathrm{P}$. TEM/EDS analysis showed that this phase contained negligible $\mathrm{P}$ and only 2 at $\% \mathrm{Ni}$.

(3) The maximum fluidity length decreases when $P$ is added to $\mathrm{Sn}-0.7 \mathrm{Cu}-0.05 \mathrm{Ni}$ melts. The most dramatic decrease in fluidity length occurs in the range 20 to 90 ppm P (nominal addition of 70 to $200 \mathrm{ppm} \mathrm{P}$ ).

(4) $\mathrm{Sn}-0.7 \mathrm{Cu}-0.05 \mathrm{Ni}$ solidifies with a near-eutectic microstructure whereas, when $\mathrm{P}$ is added to this alloy, a significant volume fraction of primary $\mathrm{Sn}$ dendrites forms once the $\mathrm{P}$ content exceeds $\sim 0.01$ mass $\% \mathrm{P}$.

\section{Acknowledgements}

This research had been conducted under the international cooperation research program between the University of Queensland, Australia and Nihon Superior Company, Japan. The authors thank Mr. Y. Guo, centre for microscopy and microanalysis (CMM) at the University of Queensland for his assistance with TEM analysis.

\section{REFERENCES}

1) T. Nishimura: Lead-free solder, International Patent No. EP1043112, (2000).

2) T. Nishimura: Lead-free solder alloy, US Patent No. US6180055, (2001).

3) T. Nishimura: Materia Japan 43 (2004) 651-654.

4) C. M. Gourlay, J. Read, K. Nogita and A. K. Dahle: Journal of Electronic Materials 37 (2008) 51-56.

5) T. Ventura, C. M. Gourlay, K. Nogita, T. Nishimura, M. Rappaz and A. K. Dahle: Journal of Electronic Materials 37 (2008) 32-39.

6) M. C. Flemings: Solidification Processing. (New York: McGraw-Hill, 1974).

7) D. V. Ragone, C. M. Adams and H. F. Taylor: Transactions of the American Foundrymen's Society 64 (1956) 653-657.

8) S. Furuseth, A.-K. Larsson and R. L. Withers: Journal of Solid State Chemistry 136 (1998) 125-133.

9) F. J. Garcia-Garcia, A. K. Larsson and S. Furuseth: Journal of Solid State Chemistry 166 (2002) 352-361.

10) M. Hansen and K. Anderko: Constitution of Binary Alloys. (McGraw Hill, 1958).

11) A. K. Larsson, L. Stenberg and S. Lidin: Acta Crystallogr., Sec. B 50 (1994) 636-643.

12) A. Westgren and G. Phragmen: Z. Anorg. Chem 175 (1928) 80-89.

13) A. Gangulee, G. C. Das and M. B. Bever: Metall. Mater. Trans. B 4 (1973) 2063-2066.

14) K. Nogita, J. Read, T. Nishimura, K. Sweatman, S. Suenaga and A. K. Dahle: Mater. Trans. 46 (2005) 2419-2425.

15) L. Snugovsky, P. Snugovsky, D. D. Perovic and J. W. Rutter: Materials Science and Technology 22 (2006) 899-902.

16) J. Campbell: Castings. 2nd ed. (Butterworth Heinemann, 2003) pp. 7482.

17) T. Ventura, K. Nogita, C. M. Gourlay, T. Nishimura, M. Rappaz and A. K. Dahle: 5th Decennial International Conference on Solidification Processing. (Sheffield, UK, 2007) pp. 651-655. 